\title{
Linking energy and tourism: energy efficiency in hotels of northeast of Mexico
}

\section{Enlazando turismo y energía: eficiencia energética en hoteles del noreste de México}

\author{
José Raúl Luyando Cuevas ${ }^{1 *}$, José Vicente Jaramillo Escobedo², María Florencia Zabaloy ${ }^{3}$, Carina Guzowski $^{4}$ \\ ${ }^{1}$ PhD, Full Time Professor in Instituto de Investigaciones Sociales, Universidad Autónoma de Nuevo León, México; E-mail: jose.luyandocvquanl.edu.mx \\ ${ }^{2}$ PhD Student, Instituto de Investigaciones Sociales, Universidad Autónoma de Nuevo León, México; E-mail: vjaramilloجddocentes.uat.edu \\ ${ }^{3}$ PhD Student, Departamento de Economía, Universidad Nacional del Sur; Argentina; E-mail: florencia.zabaloyquns.edu.ar \\ ${ }^{4}$ Carina Guzowski, PhD, Full Time Professor in Departamento de Economía, Universidad Nacional del Sur; Argentina; E-mail: cguzowacriba.edu.ar \\ * Corresponding autor: José Luyando jose.luyandocvquanl.edu.mx
}

\section{ABSTRACT}

The objective of this research is to find common characteristics between hotels that apply energy efficiency and renewable energy measures in the hotel zone of Miramar beach in Tamaulipas. The data was obtained through a poll to hotels in the region studied. The analysis is conducted with the Qualitative Comparative Analysis (QCA) technique, considering different variables, such as the number of stars and the room rates. Results show that hotels with 4 or 5 stars are characterized by implementing more procedures aimed to achieve energy efficiency. Meanwhile, hotels with low stars are characterized by being very heterogeneous in adopting those policies.

Keywords: Energy efficiency, Tourism, Hotels.

\section{RESUMEN}

El objetivo de esta investigación es encontrar características comunes entre los hoteles que aplican medidas de eficiencia energética y energía renovable en la zona hotelera de la playa Miramar en Tamaulipas. Los datos se obtuvieron a través de una encuesta a hoteles en la región estudiada. El análisis se realiza con la técnica de Análisis Cualitativo Comparativo (QCA), considerando diferentes variables, como el número de estrellas y las tarifas de las habitaciones. Los resultados muestran que los hoteles de 4 o 5 estrellas se caracterizan por implementar más procedimientos destinados a lograr la eficiencia energética. Mientras tanto, los hoteles con estrellas bajas se caracterizan por ser muy heterogéneos en la adopción de esas políticas.

Palabras Clave: Eficiencia energética, turismo, hoteles. 


\section{INTRODUCTION}

The link between energy and tourism has a great emerging field of study. Currently, one of the main topics in energy research is energy efficiency because the policies in that sense can reduce Greenhouse Gases (GHG) emissions, improve energy security at national level, and generate savings, among other benefits.

The relationship between electric power and tourism has been characterized by the recognition that the first is a key input driver of the second: The electricity is essential for services like heating, cooling, and lighting (between others). Therefore, the discussion about the importance of good practices regarding the use of energy is a crucial issue for the sector since on one hand; it implies reducing the energy bill for hotels and, on the other hand, contributes to mitigate global climate change. Therefore, energy efficiency plays a key role in the sustainability development of the tourism sector. For example, using renewable energy is considered a crucial way to increase the eco-efficiency of destinations and to achieve tourism sustainability. Some empirical results suggest that an improvement in energy efficiency practices simultaneously benefits the sustainability of both tourism development and the environment (Wang and Wang, 2018). Consequently, it is important to note that energy use is an aspect that needs to be integrated into the discussion on sustainable tourism development (Gosslin, 2000).

It is important to note that, according to the American Council for an Energy-Efficient Economy (ACEEE), Mexico was the country that improved the most regarding energy efficiency between 2016 and 2018. This improvement was mainly achieved in the industry sector. Nevertheless, there is still potential in other sectors such as transport, building and tourism activities -considering that tourism of large-scale beaches is one of the main economic activities in Mexico. Therefore, this paper explores the use of energy in hotels located on a beach named Miramar in the municipality of Madero in the state of Tamaulipas in the Northeast of Mexico; accordingly the objective of the research is to find if the star rating of each hotel has influenced the application of certain energy efficiency measures in the last ones.

\section{LINKING TOURISM, ENVIRONMENTAL AND ENERGY}

Tourism represents an important share of worldwide economic activity and in many countries it has contributed to its economic development, generation of income and employment. In particular, this first happed in European countries and in the United States after of World War II (Jones, 2017: 115) and then it was extended to the rest of the world. At the same time, it is in a certain way a complex economic activity as it interacts with many sectors, levels and interests (Carter, 1995 in Sharpley, 2009). In other words, tourism is heavily cross-linked with building, aviation, and automotive industries and there are no materials, tools, or technologies that are exclusive to tourism (Buckley, 2011).

In this sense, tourism should not be seen as a simple system of demand and supply but rather as a wider system in which both demand and supply of tourism influence and are influenced by different external factors, for instance political, economic, technological, socio-cultural, legislative and environmental factors (Sharpley, 2009).

Despite the positive impacts, tourism represents a trade-off as it generates several environmental negative impacts that depend on the types and components of tourism. Those impacts include: increase in water and energy consumption, destruction of landscape, increase in waste, loss of biodiversity and alteration of ecosystems, forest fires, among others (Barrera and Bahamondes, 2012; Santamarta, 2000). It is extremely necessary to consider these impacts as tourism rely on attractive of its natural resources, such as pleasant climate, clean water, plants, and etcetera (Tang, 2015).

Another important aspect of the tourism activity is that it requires vast amounts of energy for the production of its products, services, and visitor experiences. The increase in tourism leads to an increase in energy consumption. Hence, energy becomes a key component, as it facilitates transportations of travelers and provides amenities and supports facilities at the destinations visited (Kelly and Williams, 2007). Furthermore, energy consumption in tourism destinations is greater than energy consumption in a similar-sized non-tourist community due to the use of ener- 
gy-intensive technologies that offer tourist amenities (Tabatchnaia-Tamirisa et al., 1997 in Kelly and Williams, 2007).

Between the different types of accommodations, such as hotels, motels, bed and breakfast, among others, hotels require relatively more energy because they have energy-intensive facilities (bars, restaurants, swimming pools, etc.) (Becken et al., 2001 in Kelly and Williams, 2007). Moreover, in the case of city hotels, as they are connected to municipal utilities, they impact the power and water supplies, garbage disposal and sewage treatment systems (Buckley, 2011). Thus, development planning and environmental regulation should be integrated into local government law and planning (Buckley, 2011).

One way to mitigate the environmental impact of tourism, and in particular the hotel industry impact, is to implement renewable energies and energy efficiency strategies in these establishments. The aim of these measures is to decrease energy consumption and, as much as possible, to change the type of energy sources used, from fossil fuels to more clean energies, and at the same time to avoid wasting energy resources that scarce, without compromising the satisfaction of visitors and their needs. These two actions tend to reduce $\mathrm{CO} 2$ emissions derived from energy consumption, and consequently boost an environmental improvement.

Currently the world faces a dilemma that is how to achieve a balance between the potential development contribution of tourism and its negative consequences (Sharpley, 2009). With an effectively management of tourism, sustainable development can be achieved while maintaining a high quality of environment through coordination of tourism and the environment (Tang, 2015). In addition, understanding the relationship between energy consumption, environment, and tourism is of interest to not only to policymakers but also to professionals (Katircioglu et al., 2014).

The development of sustainable tourism is impossible to achieve in the absence of appropriate policies, planning, and management, especially in the case of developing countries. The peripheral or economically disadvantaged regions are increasingly focusing on tourism as a means of stimulating economic and social regeneration and therefore tourism has come to represent a vital pillar of their development policies (Sharpley, 2009).

\section{THE IMPORTANCE OF TOURISM IN MEXICO}

Worldwide the importance of tourism is reflected in the main indicators that measure the behavior of tourism activity. Among these, there are two indicator of great relevance: the number of tourists arriving at the destination and the income generated to the host country.

Mexico has positioned itself as one of the main tourist destinations worldwide. According to the World Tourism Organization (UNWTO) in 2018, Mexico ranked 16th by concept of foreign currency income and 7th in terms of arrival of tourists attracting. These arrivals, in percentage terms, represent almost $3 \%$ of the total number of tourists in the world (Ministry of Tourism [SECTUR], 2019). Consequently, Mexico has improved its positioning in the world ranking of tourism since 2013 , going from the 15 th position in 2013 to the seventh in 2018.

Value added from tourism sector, in particular from accommodation services, hotels and restaurants, has increased over the years, as it is shown in Figure 1. At the same time, when analyzing the evolution of energy consumption from the commercial sector, in which tourism is included, it can also be seen an increase in the last years. In other terms, in Mexico, the level of economic activity related to tourism and its corresponding energy consumption is coupled. 
Figure 1. Evolution of commercial energy consumption and added value of hotel industry 2000-2016.

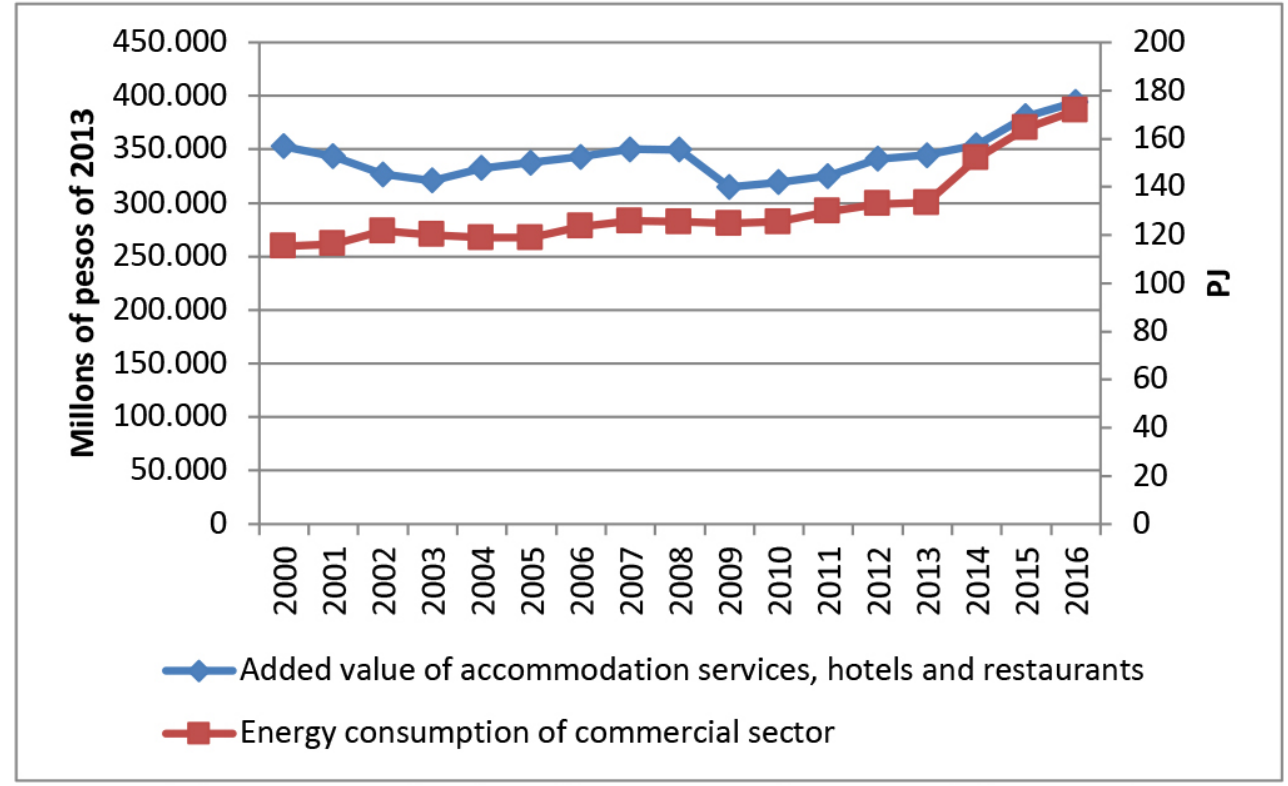

Source: National Commission for the Efficient Use of Energy (CONUEE for its acronym in Spanish)

Regarding the tourist destinations of Mexico, especially those of the sun, sand and sea type, they are concentrated in the Caribbean Sea such as the case of Cancun and the Riviera Maya in the state of Quintana Roo, Los Cabos in the state of Baja California Sur and Puerto Vallarta in the state of Jalisco. These four sun and beach destinations are the most visited by both foreign and domestic tourists (Forbes, 2016).

As a result of the concentration of sun and beach tourist destinations, in recent years the Mexican government has been oriented policies to diversify the tourism supply either by type of tourism or by geographical spaces. One of the strategies implemented by the federal government in the period 2013-2018 was the creation of the Tourism Destination Competitiveness Agendas (ACDT) in 44 priority tourist destinations, being one of them the destinations called Tampico Madero. The aim of the ACDT was to "diagnose their situation and to undertake a program of actions, in close coordination between the Federation and local governments, with the participation of other stake- holders of each destination" (SECTUR, 2013, p. 9). This policy of the ACDT shows the interest of the federal government to consolidate the most important touristic destinations as well as to identify those emergent destinations of regional importance, such as Miramar beach which is mainly characterized by sun and beach tourism, which can be exploited with better planning and it can improve the quality of life of the local population.

The recent increase in tourist activity in the conurbation of southern Tamaulipas that comprise the municipalities of Ciudad Madero, Tampico and Altamira is reflected in the tourist infrastructure, as there are 147 temporary accommodation establishments in the area, $86 \%$ of which are in Tampico and Ciudad Madero. Likewise, hotel occupancy has experienced a rise from $28.93 \%$ occupancy in 2010 to rates of $50.35 \%$ in 2017 , which is a percentage increase of around $74 \%$ in 7 years (SECTUR, 2017). However, this is still below the national average, which was $61.1 \%$ for 2017 (SECTUR, 2017), as it can be seen in Figure 2. 
Figure 2. Percentage of hotel occupancy in Tamaulipas in 2008-2017

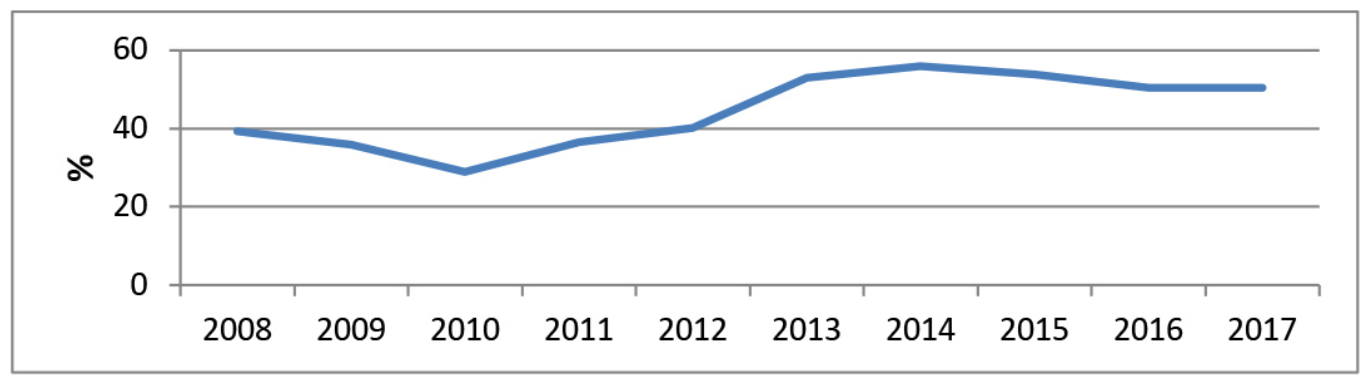

Source: Own elaboration with statistical data of the Ministry of Tourism. Tourist Information by Federal Entity. SECTUR (2017)

The traditional economic activities in these three municipalities have been: industry and primary activities in Altamira, exploitation of hydrocarbons and basic and secondary petrochemicals in Ciudad Madero, and commercial activities and tourist services in Tampico (PNUMA et al, 2015). Nevertheless, the municipalities of Tampico and particularly Ciudad Madero, are currently in a process of modernization and creation of tourism infrastructure (Gobierno del Estado de Tamaulipas, 2018), a tourism industry which gradually will become one of the main activities in this region.

\section{STUDY AREA AND DATA}

For this research, the main hotels in the study area were located and classified into five hotel zones: Madero-Miramar Beach, Madero, Tampico-Hidalgo Avenue, Tampico downtown area and Altamira. According to the INEGI (2017) for the year 2015 in Altamira there were 20 hotels, in Ciudad Madero 49 and in Tampico 78, i.e. there were 147 in total. Given the environment of insecurity experienced by the entity, it is difficult for hotels to provide their data to any person (even in the case of scientific studies), due to the distrust that this situation has created. However, the Hotel Association of the South of Tamaulipas A.C. provided us with a list of their 36 affiliates and their endorsement, which allowed us to carry out the surveys.

The survey was constructed following the main guidelines to certify the green or sustainable lodgings related to the energy efficiency that proposed organizations such as: Green Lodging Program (Florida Department of Environmental Protection [DEP], 2018) and the Key Green Program certification (Foundation for Environmental Education [FEE], 2016). The survey was structured in two parts called: socioeconomic characterization and energy characterization of the establishment. The latter was divided into maintenance, equipment, and construction of the establishment.

It is important to note that we faced some problems in the field study. In effect, in 5 cases we did not find the person that could answer the survey, in 4 cases they refused to answer it and in 2 cases the hotels were not in the indicated address. Therefore, we can say that the 25 cases are a sample size which was obtained statistically taking a confidence level of $95 \%$ and a margin of error of $18 \%$, but where the sampling was not random.

\section{METHODOLOGY: THE QUALITATIVE COMPARATIVE ANALYSIS APPROACH}

The Qualitative Comparative Analysis (QCA) constitutes a relevant methodological tool for social sciences because it employs Boolean logic to examine the relationship between an outcome and all binary combinations of multiple predictors (Longest and Vaisey, 2008).

The objective of using QCA is to: summarize data, check the coherence of the data with claims of subset relations, test existing hypotheses and theories, overview the basic assumptions of the analysis, and develop new theoretical arguments (Schneider and Wagemann, 2010). The advantage of this technique is that data with a low to moderate sample size (small $\mathrm{N}$ ), such conventional survey data, can be used. In addition, it allows the number of variables to be greater than the number of cases (Areiza Madrid, 2017). It is important to note that through QCA analysis we cannot prove causal relationships but rather we can reveal patterns of associations across sets of cases or observations (Legewie, 2013). 
In this paper, the research question is: the star rating of hotels located in northeast Tamaulipas in the Gulf of Mexico influences the grade of attention that they give to energy efficiency and renewable energy?
For this purpose, we divide the hotels in two ranks: 0 - for hotels with two or three stars or no rank (HLS), and 1 - for hotels with four and five stars (HMS). In addition, we construct the data table defining different conditions that may influence the outcome mentioned above in Table 1.

Table 1. Conditions to asses in the hotels of South Tamaulipas

\begin{tabular}{|c|c|c|c|}
\hline \multirow[t]{2}{*}{ Condition } & \multirow[t]{2}{*}{ Code } & \multicolumn{2}{|c|}{ Explanation } \\
\hline & & Rank 0 & Rank 1 \\
\hline Hotel rates ${ }^{i}$ & $\mathrm{HR}$ & 15.40 USD to 77 USD & 78 USD to more than 128 USD \\
\hline $\begin{array}{l}\text { Does the hotel register historical } \\
\text { energy consumption? }\end{array}$ & KEC & Yearly or not done & Daily, monthly or bimonthly \\
\hline $\begin{array}{l}\text { Does the hotel use eco-friendly } \\
\text { certification or renewable energy sources? }\end{array}$ & RES & No or does not know & Yes, between $50 \%$ and $100 \%$ \\
\hline $\begin{array}{l}\text { Has the hotel received inspection visits from } \\
\text { a government entity related to the } \\
\text { energy efficiency? }\end{array}$ & INS & No or does not know & $\begin{array}{l}\text { Municipal, State, } \\
\text { Federal or all levels. }\end{array}$ \\
\hline $\begin{array}{l}\text { Does the hotel have a formal policy } \\
\text { regarding mechanisms that save energy? }\end{array}$ & $\mathrm{FP}$ & No or does not know & Yes \\
\hline $\begin{array}{l}\text { When the hotel was built, the effective } \\
\text { use of shadow to reduce climate } \\
\text { costs was considered? }\end{array}$ & $\mathrm{BH}$ & No or does not know & Yes \\
\hline
\end{tabular}

Source: Own elaboration

As it can be seen, the conditions are related to the hotel rates, the registration of energy consumption, the inclusion of certifications or renewable energy, visits from governmental agencies to improve energy efficiency, hotel policy regarding energy savings and the use of shadow in the design of the building. Following this design, the analytic strategy QCA will be used to answer the research question mentioned before. To carry out the empirical analysis the fs/QCA 2.5 Software was used.

\section{RESULTS}

After defining the conditions in the previous section, the next was to find and resolve contradictions and duplicated configurations. In this research, one contradiction and six duplicate cases were found and thus the size of the sample decreased to $18(\mathrm{~N})$.

In the first stage, the necessity test was made, which indicated us that keeping a record of energy consumption on a daily, monthly or bi-monthly basis is a condition that characterized the 4 and 5 stars hotels (considering a consistency threshold largest to 0.9 , it was of 0.92 and its coverage was 0.86 ). In this sense, the last indicates need but not causation. If we perform the same procedure for hotels with 2 and 3 stars or without rank, the test indicates us that the absence of certified eco-friendly or renewable energy sources and prices between 15.40 to 77 dollars are necessary conditions for these type of establishments (in both cases its consistency was 1 , but its coverage was 0.33 when some authors say that it should be highest than 0.5). In a second stage, the truth table analysis was made. The software fsQCA gives three different solutions: complex, parsimonious and intermediate. When comparing the most parsimonious solution with the intermediate, it is observed that both are identical in their combinations and in their values of coverage and consistency. Both contain two routes that explain the result of interest. Before explaining the solution, we have to show the table consistency. The first point is to guarantee that consistency 
and coverage solutions are greater than 0.75 (a situation that is fulfilled, as can be noted in the table 2), because if the indicators are below that threshold it means that the model is a wrongly specified. Regarding raw coverage, the greater the numerical value is, the greater the empirical relevance, i.e., it is possible to explain a major number of cases where this result occurred. As we can see from table 2: the highest value is 0.54 after that, the indicator falls to
$0.31,0.23,0.15$ and 0.077 . In the same way, the unique coverage scores indicate at first look the number of cases explained, but they also show the overlap between recipes. The degree of overlapping coverage is 0.53 ; considering the data set, the score tells how strong the cases cluster is along certain causal dimensions and, individually, it shows how many cases with the occurrence outcome can be explained in more than one way.

Table 2. Parsimonious and intermediate solution

\begin{tabular}{|c|c|c|c|}
\hline Four and Five Starsi & Raw Coverage & Unique Coverage & Consistency \\
\hline $\mathrm{HR}$ & 0.230769 & 0.076923 & 1.00000 \\
\hline RES & 0.230769 & 0.076923 & 1.00000 \\
\hline KEC* BH & 0.538462 & 0.153846 & 1.00000 \\
\hline KEC*INS* FP & 0.153846 & 0.0000 & 1.00000 \\
\hline KEC* INS*FP & 0.307692 & 0.0000 & 1.00000 \\
\hline INS* FP**BH & 0.076923 & 0.0000 & 1.00000 \\
\hline INS*FP*BH & 0.076923 & 0.0000 & 1.00000 \\
\hline Solution Coverage & \multicolumn{3}{|l|}{0.846154} \\
\hline Solution Consistency & \multicolumn{3}{|l|}{1.000000} \\
\hline
\end{tabular}

Source: own elaboration

Finally, if the model has a consistency score equal to 1 in all cases (the third column), this tells us that the cases fit the patterns identified by QCA, or that the contradictions that certain cases pose are low.

Considering all the above and considering the higher scores in raw and unique coverage, an equation can be obtained to try to explain the research question ${ }^{\text {iii : }}$

$$
\mathrm{HR}+\mathrm{RES}+\mathrm{KEC} * \mathrm{BH}->\mathrm{HMS}
$$

The outcome can be read as follows: the hotels that have a high rate (more than 78 dollars) are characterized, overall, for being the ones that have four or five stars. These last ones are also characterized by being those that claim to use renewable or eco-certified energy sources. But, above all, they have this rating because they have at the same time a concern about their electric power consumption (since these keep track daily, monthly or bimonthly follow-up of this) and also because they did not consider the shadow when the hotel was builtiv. The latter was a measure which could have helped to save electricity since the temperature inside the hotel would have been less and this would imply lower costs in terms of air conditioning. We suppose that some hotels were built several years ago when the electricity cost and air pollution were not important factors for owners and the social awareness for the environment was not as strong as it is now, but nowadays it has become a quotidian issue that worries many nations, firms and a large number of citizens in the world. Regarding the electric power consumption, these hoteIs worried about the current problems of environmental pollution because it entails costs for them (the high use of electric power and its rising prices). In the same way, today more people is aware about environmental problems, thus, hotel managers are implementing measures to mitigate environmental impact as a marketing strategy because tourists with high purchasing power find these actions interesting and are willing to pay more for eco-friendly tourism.

On the other hand, when analyzing the case of hotels with 2 or 3 stars hotels or without sorting, the results show that we could have been including irrelevant conditions or inadequate indicators. According to the above parameters used, i.e., the conditions used to characterize this type 
of hotels were not the most appropriate because the solution coverage had a score of 0.6 , under 0.75 , and this denotes a badly specified model for this type of establishments. However, it should be noted that the results of the conditions maintain the direction that was expected, i.e., that these hotels have rates between 15.40 to 77 dollars; they do not use eco-friendly certification or renewable energy sources; they have not received inspection visits from a government entity related to the energy efficiency and that they do not have formal policy regarding mechanisms that save energy.

To explore more about the conditions that shape this type of hotels (with 2 or 3 stars or without sorting), the following exercise was made:

$$
\sim H R=\text { f(stars, KEC, RES, INS, FP, BH) }
$$

Where $\sim \mathrm{HR}$ are hotels with rates between 15.40 and 77 dollars. Therefore, now our dependent variable is the price of these hotels and the stars now is an independent variable. In this exercise the solution coverage had a score of 0.867 above 0.75 , i.e. the specified model is right. The problem with this application is that there are many results and few possibilities for reducing similar terms, i.e., this kind of hotels have a diversified combination of conditions. The aim of the technique is abstracting in few characteristics the conditions of all these hotels, which in this case is not possible.

\section{DISCUSSION AND CONCLUSIONS}

In this research, it was found that the hotel's stars in the studied region are related to its level of energy efficiency. It seems that hotels with four and five stars with higher rates and high energy demand are the most interested in applying energy efficiency and renewable energy policies to reduce their costs, which suggest that the main technological changes that reduce energy intensity in hotels are more strongly related with their capacity to invest than to the public policies implemented by the municipality or the state.

This could be because: they have the major's profits and could make big and small investments expecting these to be successful in reducing costs in the medium and long term. On the income side, they can take advantage of this situation and advertise themselves as socially responsible companies with the environment, with the purpose of at- tracting tourists from developed countries because we assume that they have a greater awareness of the problem and a greater purchasing power.

Indeed, it could be assumed that the bet of these hotels is getting more benefits in the medium term from at least four factors: lower costs by reducing energy use, less use of variable capital by the implementation of better technology, the awareness created in the hotel guests (less use of inputs such as energy and water) and the possibility to increase prices -if there is a high demand of tourists with environmental awareness, especially if they come from developed regions such as the USA or Europe-.

On the other hand, the hotels with 2, 3 or without stars are very diverse in the application of energy efficiency policies and it is impossible to summarize their characteristics in order to group them easily, therefore it is difficult to propose any public policy to help them to adopt new technologies to lower their energy demand. A situation even more distressing appears when we consider that the price of electricity is increasing in Mexico and it is one of main inputs used by hotels. Indeed, it should be noted that the electricity cost for this industry in the country is increasing, like Reyna Quiroz (2018) shows: "The Mexican Association of Hotels and Motels (AMHM) reported increases of up to 300 percent so far this year in the charges of the Federal Electricity Commission (CFE) for electricity consumption, which puts at risk the financial viability of the companies and the tourist activity in general, and announced a common front of businessmen who will intervene against the methodology that defines the level of electricity rates".

The situation above could also create other problems in the region because it is the small and medium businesses which generate the majority of jobs in Mexico. Therefore, if only the hotels with 4 or 5 stars have the capacity to lower costs and increase benefits via changes in technology -especially in energy efficiency-, this could act against the hotels with 2 and 3 stars which represent the majority of hotels in the state of Tamaulipas and also in the area of study. If these hotels have not enough income, they could fall into bankruptcy and leave unemployed many native people. In addition, they are firms that generally demand regional products and generate internal productive chains that create investment and employment. Furthermore, many of them keep the traditional culinary culture of the place and this could be lost. 
Finally, this research shows that energy efficiency can add value in the tourism sector. As mentioned, in Mexico, the tourism sector has improved its position in the world, so investing in a more efficient and sustainable energy management model can offer great competitive advantages over other industries. Renewable energies and energy efficiency policies accompanied by a mix of up-to-date technologies and knowledge, with accessible financing and adequate regulations, will allow a deep cultural change, in addition to economic savings, mitigation and adaptation to climate change.

\section{REFERENCES}

Barrera, C. \& Bahamondes, R. (2012). Turismo Sostenible: Importancia en el cuidado del medio ambiente. Revista Interamericana de Ambiente y Turismo-RIAT, Vol. 8, No 1, pp. 50-56.

Buckley, R. (2011). Tourism and environment. Annual Review of Environment and Resources, Vol. 36, pp. 397-416.

Forbes (2016). Los 4 destinos de playa más visitados en México. Https://www.forbes.com.mx/los-4-destinos-playa-mas-visitados-mexico/. Accessed 14th of February 2019 at 10:45.

Gobierno del estado de Tamaulipas (2018). Inaugura gobernador infraestructura para fortalecer modernidad y turismo en la zona sur. Https://www. tamaulipas.gob.mx/administracion/2018/03/ inaugura-gobernador-infraestructura-para-fortalecer-modernidad-y-turismo-en-la-zona-sur/. Accessed 2th March 2019 at 11:00.

Gossling, S. (2000). Sustainable tourism development in developing countries: some aspects of energy use. Journal of Sutainable Tourism, Vol. 8, $\mathrm{N}^{\circ} 5$, pp. 410-425. Https://www.tandfonline.com/doi/ abs/10.1080/09669580008667376. Accessed 14th February 2019 at 11:00.

Instituto Nacional de Estadística y Geografía. (2013). Conociendo Tamaulipas. Https:// www.inegi.org.mx/app/biblioteca/ficha.html?upc $=702825004294$. Accessed 3th March 2019 at 9:30.
Jones, G. (2017). Profits and Sustainability: A history of green entrepreneurship. United Kingdom, OXFORD University Press.

Katircioglu, S., Feridun, M. \& Kilinc, C. (2014). Estimating tourism-induced energy consumption and CO2 emissions: The case of Cyprus. Renewable and Sustainable Energy Reviews, Vol. 29, pp. 634-640.

Legewie, N. (2013). An introduction to applied data analysis with qualitative comparative analysis. In Forum Qualitative Sozialforschung/Forum: Qualitative Social Research (Vol. 14, No. 3).

Programa de las Naciones Unidas para el Medio Ambiente, Gobierno del Estado de Tamaulipas y Secretaría de Medio Ambiente y Recursos Naturales. (2015). Perspectivas del Medio Ambiente y Cambio Climático en el Medio Urbano: ECCO Zona Conurbada del Sur de Tamaulipas. México. Http://www. une.edu.mx/ECCO.pdf. Accessed 14th February 2019 at 11:00.

Reyna, J. (2018). Se unen hoteleros contra cobros excesivos de la CFE. La jornada. Https://www.jornada. com.mx/ultimas/2018/09/20/se-unen-hoteleros-contra-cobros-excesivos-de-la-cfe-7379.html. Accessed 30th September 2018 at 11:00.

Santamarta, J. (2000). Turismo y medio ambiente. World Watch. Http://www.nacionmulticultural.unam.mx/ mezinal/docs/6372.pdf. Accessed 22th January 2019 at $12: 00$.

Schneider, C. Q. \& Wagemann, C. (2010). Standards of good practice in qualitative comparative analysis (QCA) and fuzzy-sets. Comparative Sociology, Vol. 9, N³, pp. 397-418.

Secretaría de Turismo. (2013). Agenda de Competitividad Turística de la Ciudad de México (ACTCM 2013). Http://www.sectur.gob.mx/wp-content/ uploads/2015/02/PDF-Ciudad-de-Mexico.pdf. Accessed 22th January 2019 at 11:00.

Secretaría de Turismo. (2017). Actividad hotelera en México: Porcentaje de ocupación. En Portal del Sistema Nacional de Información Estadística y Geográfica de Turismo-SNIEGT. Https://www.datatur. 
sectur.gob.mx/SitePages/ActividadHotelera.aspx. Accessed 14th February 2019 at 11:00.

Secretaría de Turismo. (2019). Ranking Mundial del Turismo Internacional. En Portal del Sistema Nacional de Información Estadística y Geográfica de Turismo-SNIEGT. Https://www.datatur.sectur.gob. $\mathrm{mx} /$ SitePages/RankingOMT.aspx. Accessed 16th March 2019 at 11:00.

Sharpley, R. (2009). Tourism development and the environment: Beyond sustainability?. United Kingdom, Routledge.
Tang, Z. (2015). An integrated approach to evaluating the coupling coordination between tourism and the environment. Tourism Management, Vol. 46, pp. 11-19.

Thomas, J., O’Mara-Eves, A. \& Brunton, G. (2014). Using qualitative comparative analysis (QCA) in systematic reviews of complex interventions: a worked example. Systematic reviews, Vol. 3, N 67.

Wang Ming-Chie \& Wang Chang-Sheng. (2018). Tourism, the environment and energy policies. Tourism Economics, Vol. 24, № 7, pp. 821-838.

i The exchange rate taken was 19.5 MXN per USD

"An asterisk * is used to combine strictly both conditions (equivalent to 'And'), the plus sign + is used to combine conditions (equivalent to 'And'/'or') and a tilde is used to indicate non-membership in a condition (Legewie, 2013; Thomas et al., 2014).

iii Even if we consider raw coverage scores of 0.307692 and 0.153846 the finding should not change because if we doing a little algebra with all these terms (reducing similar terms) the consequence is that it does not aggregate anything to the outcome.

iv The movement of the sun throughout the day was not considered. 